\title{
Interactive comment on "Using
} ground-penetrating radar, topography and classification of vegetation to model the sediment and active layer thickness in a periglacial lake catchment, Western Greenland" by Johannes Petrone et al.

Anonymous Referee \#1

Received and published: 22 July 2016

The paper is well written and presented an interesting case study. Some comments and suggestions are presented in the following: Page 6, line 7: I suggest to improve the description of the system used for bathymetry. In particular, I suggested to insert the description of the GPS acquisition characteristics (e.g the acquisition has been done with or without RTK correction) and the estimated accuracy of the obtained DTM Page 7 from line 21: I suggest to improve the description of the relation between figure 4B and $4 \mathrm{C}$. If I understood correctly, $4 \mathrm{C}$ is the real section of the presented GPR section. 
If yes, I suggest to plot over figure $4 \mathrm{C}$ the limit of the permafrost reflector presented in figure $4 \mathrm{~B}$. Page 10, line 21: the indication of figure $A$ and $B$ in figure 7 is missing please improve accordingly. Figure 4: use the same order or presentation of section (e.g. change 4F with $4 \mathrm{E}$ ) Figure 7 : $A$ and $B$ are missing

ESSDD

Interactive comment on Earth Syst. Sci. Data Discuss., doi:10.5194/essd-2016-19, 2016.

Interactive

comment 